\title{
Effects of Geometrical Feature on Microstructures and Mechanical Properties of Refill Friction Stir Spot Welding 6061 Aluminum Alloy
}

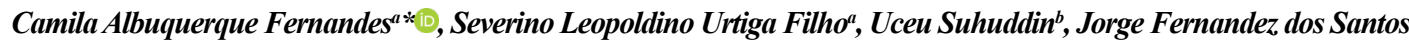 \\ ${ }^{a}$ Programa de Pós-Graduação em Engenharia Mecânica (PPGEM) Universidade Federal de Pernambuco(UFPE), \\ Recife, PE, Brasil \\ ${ }^{b}$ Helmholtz-Zentrum Geesthacht, Materials Mechanics, Solid-State Joining Processes, Geesthacht, Germany
}

Received: June 17, 2019; Revised: September 25, 2019; Accepted: October 16, 2019

\begin{abstract}
Refill friction stir spot welding (refill FSSW) is a solid state joining technology developed and patented by Helmholtz-Zentrum Geesthacht. Refill FSSW is a welding process suitable for spot joining lightweight materials in similar and dissimilar joint configuration. The result is a spot welded in lap configuration with minimal material loss and a flat surface with no keyhole. In the present study, refill FSSW was applied to join the similar 6061 aluminum alloy sheet with $1.25 \mathrm{~mm}$ thickness. The objective of this work is to investigate the influence of the hook on the microstructure and mechanical properties of the weld. The hook is a geometrical feature, formed as a result of the upward bending of the sheet interface during the sleeve plunge and retraction during welding. The weld strength had a negative correlation with the hook height, however it was concluded that the shape of hook changes according to the combination of process parameters. The highest value of the lap shear corresponded to the smallest hook height.
\end{abstract}

Keywords: refill FSSW, AA6061, hook, lap shear test.

\section{Introduction}

Refill friction stir spot welding (refill FSSW) process is a solid state welding process that was invented and patented by the Helmholtz-Zentrum Geesthacht (HZG), Germany, in which two or more sheets are joined in lap configuration ${ }^{1}$. The joining region consists of a material forming a fully consolidated weld that is flush with the original surface. The process is based on frictional heating and deformation of the workpiece produced by a non-consumable rotating tool (comprised by a clamping ring, sleeve, and probe) with a transverse displacement that creates a joint between sheets in overlap configuration. This technology is suitable for spot joining lightweight materials in similar or dissimilar joint configuration ${ }^{2}$.

The refill FSSW process is divided into four stages. Initially, sheets are clamped between a backing plate and the clamping ring; after that, the rotating tool plunges into the workpiece generating frictional heat on the upper sheet surface. While rotating in the same direction, pin or sleeve move in opposite direction to each other (one is plunged into the material while the other retracts, depending on the process variant). Plasticized material is squeezed into the space left by the retracted part until the end of the stage, when the tool parts move back towards the surface of the plate pushing the squeezed material back into the plate. At the end of the process, the result is a spot welded lap joint with minimal material loss and a flat surface without keyhole ${ }^{3,4}$.
Refill FSSW has several advantages over others spot joining technologies such as good surface quality, good reproducibility, low energy consumption and high environmental compatibility. Therefore, the potential for the use of refill FSSW in several structural components is extremely large and the benefits of replacing mechanical fastening or fusion welding techniques are significant. Since this process offers an alternative to overcome the main disadvantages of conventional spot welding processes, refill FSSW has recently received a great deal of interest from automotive and aircraft industries ${ }^{4}$. However, further research studies are necessary for improving the knowledge on this technology. The uncertainties involving weld geometric features (effective bonded area and hook) necessitate dedicated investigation to understand the dependence of the weld macrostructure and processing parameters on the mechanical properties. The objectives of this study are to investigate the effect of processing parameters on the hook formation as well as on the weld strength of similar refill friction stir spot welds of $1.25 \mathrm{~mm}$ thick AA6061.

\section{Experimental Procedure}

The material utilized in this investigation was a 6061 aluminum alloy with a sheet thickness of $1.25 \mathrm{~mm}$, whose nominal chemical composition and mechanical properties are listed in Table 1 and Table 2, respectively. 
Before welding, all sheets were cleaned with acetone to remove dirt and oil. As shown in Figure 1, all the specimens were welded in lap configuration, and the spot welds were produced on two $110 \mathrm{~mm}$ x $30 \mathrm{~mm}$ sheets overlapped by $30 \mathrm{~mm}$. All of the specimens are welded in the center of the overlap area. The refill FSSW process was carried out using a RPS 100 machine, fitted with a tool featuring a $18 \mathrm{~mm}$ diameter clamping ring, $9 \mathrm{~mm}$ diameter threaded sleeve and $6 \mathrm{~mm}$ diameter pin. This machine has a monitoring system that records parameters such as plunge depth, rotational speed, axial load and welding time. Three different processing parameters were varied: rotational speed (RS) of 1300 and $1500 \mathrm{rpm}$, plunge speed (PS) of 3.5, 4.0 and $4.5 \mathrm{~mm} / \mathrm{sec}$, and plunge depth (PD) of 1.3, 1.4 and $1.5 \mathrm{~mm}$ comprising 5 conditions (see Table 3 for process parameter matrix).

Macrostructure and microstructural characterization have been conducted in the cross-sections of welded specimens. For microstructure analysis, the samples were carefully cut.
The samples were then embedded in a transparent mounting resin (Clarocit) under pressure to avoid cavities in the resin, groud and polished. The samples were etched using Barker's reagent. The metallurgical assessment was performed using a Leica DM IRM Optical Microscopy (OM), equipped with the software Leica Application Suite 3.5. Metallurgical analysis was performed with the purpose of revealing and characterizing the hook formation. Furthermore, the quality of welds produced by the refill FSSW process were evaluated and correlate with the mechanical testing results.

Lap shear test was performed using a screw-driven Zwick/ Roell testing machine with a load capacity of $200 \mathrm{kN}$ and TestXpert software which provided the tensile properties. A constant cross head speed of $2 \mathrm{~mm} / \mathrm{min}$ was used and the tests were performed at room temperature. For each condition, the strength was averaged over three specimens with the peak load being measured.

Table 1. Chemical composition

\begin{tabular}{ccccccccc}
\hline $\mathrm{Mg}$ & $\mathrm{Si}$ & $\mathrm{Fe}$ & $\mathrm{Cu}$ & $\mathrm{Cr}$ & $\mathrm{Mn}$ & $\mathrm{Ti}$ & $\mathrm{Zn}$ & $\mathrm{Al}$ \\
\hline $0.8-1.2$ & $0.4-0.8$ & Max. 0.7 & $0.15-0.4$ & $0.04-0.5$ & Max. 0.15 & Max. 0.15 & Max. 0.25 & Balance \\
\hline
\end{tabular}

Table 2. Mechanical properties

\begin{tabular}{ccccc}
\hline \multicolumn{2}{c}{ Stress (MPa) } & Hardness, Vickers (HV) & Shear stress (MPa) & Elongation (\%) \\
\hline Tensile stress (MPa) & Yield stress (MPa) & & 207 & Min. 10 \\
\hline Min. 260 & Min. 240 & 107 & 207 & \\
\hline
\end{tabular}

Table 3. Process parameter matrix - LSS (N)

\begin{tabular}{cccc}
\hline RS $(\mathrm{rpm})$ & PD $(\mathrm{mm})$ & PR $(\mathrm{mm} / \mathrm{sec})$ & LSS $(\mathrm{N})$ \\
\hline 1300 & 1.4 & 4.0 & 6243 \\
1300 & 1.3 & 4.0 & 6111 \\
1300 & 1.5 & 4.0 & 5895 \\
1300 & 1.4 & 3.5 & 6008 \\
1500 & 1.4 & 4.0 & 6025 \\
\hline
\end{tabular}

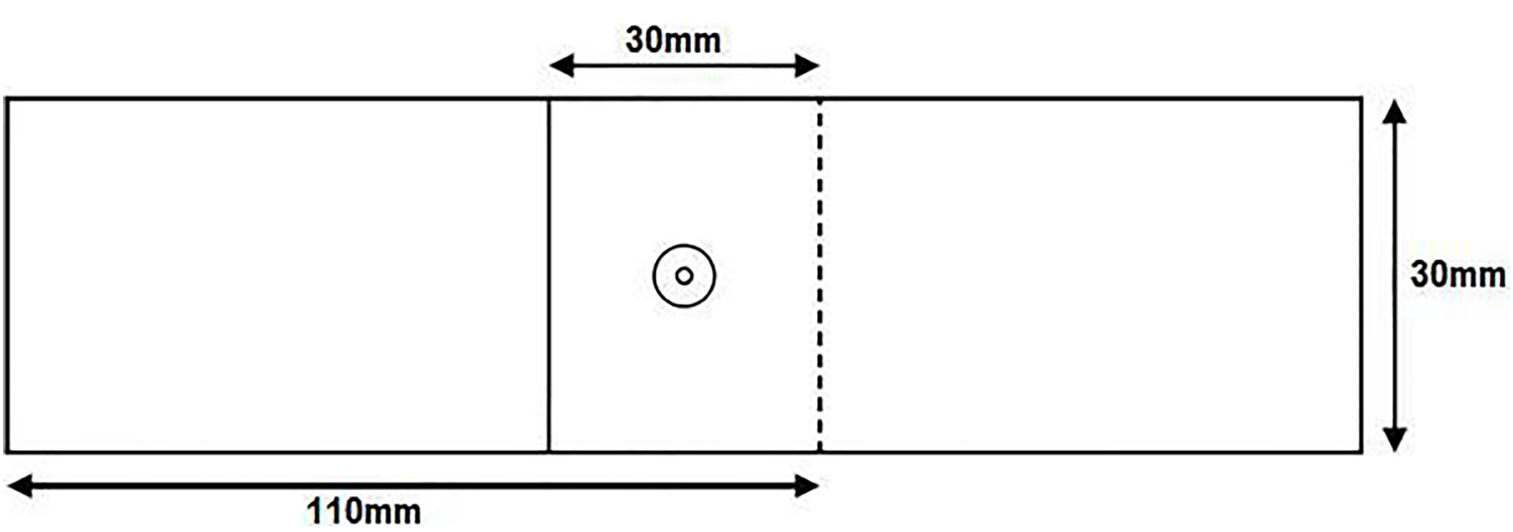

Figure 1. Schematic representation of the sample. 


\section{Results and Discussion}

\subsection{Microstructure characterization of the weld zone}

A macrostructural observation shows different weld regions, as presented in Figure 2. A microstructural investigation revealed three distinct weld regions: the stir zone (SZ), the thermo-mechanically affected zone (TMAZ) and the base material $(\mathrm{BM})$ as shown in Figure $3^{2,5}$. The $\mathrm{SZ}$ is characterized by equiaxed refined grains formed due the dynamic recrystallization. TMAZ is characterized by an elongated structure pointing upwards due to plastic deformation. The BM it was not subjected to plastic deformation ${ }^{6}$.

\subsection{Hook characteristics}

The examination of the cross sections revealed geometric features common to all investigated samples: hook, partial bonding and joint line remnant, see Figure 4 . These geometric patterns are characteristic of refill FSSW joints and affect the resulting mechanical properties ${ }^{5}$.
The joint line remnant is an oxide remnant in a region between the upper and the lower sheets. It can be seen that the appearance of the joint line remnant is rather different between the center and edge of the weld. On the edge, the bonding ligament has a zigzag appearance, and in the center is a straight line, as shown in Figure 5. Its characteristic shape on the edges is a result of material flow, when the sleeve pushes the plasticized material back to its original position.

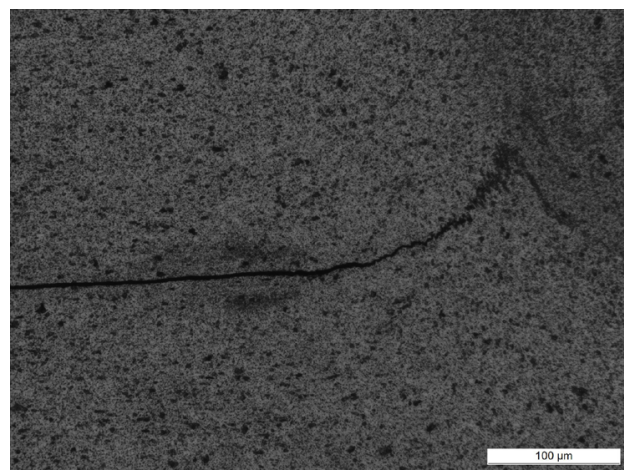

Figure 5. Edge the bonding ligament.

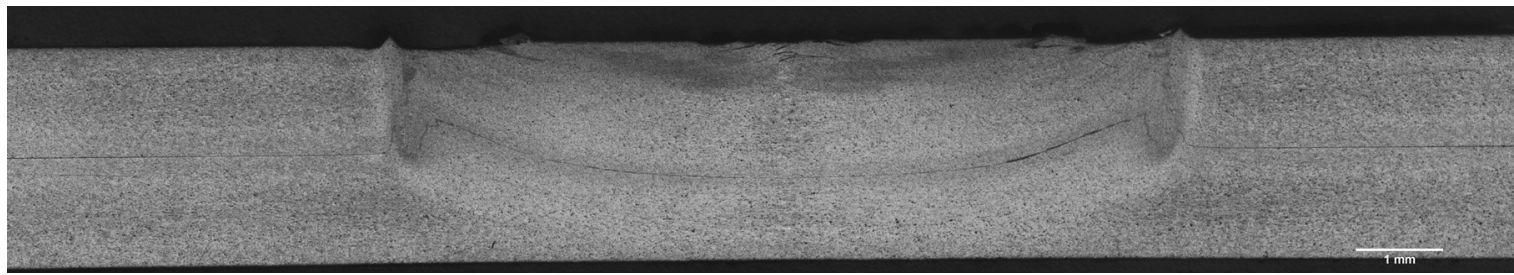

Figure 2. OM macrographs of a typical FSSW connection cross section showing the weld zones.
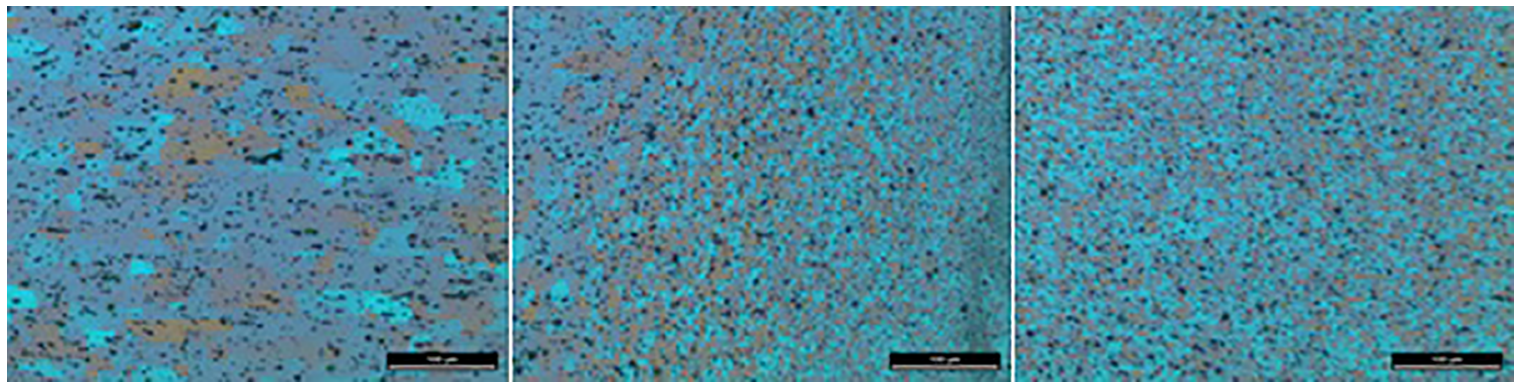

Figure 3. Grain structures in different microstructural zones (a) BM, (b) TMAZ, (c) SZ.

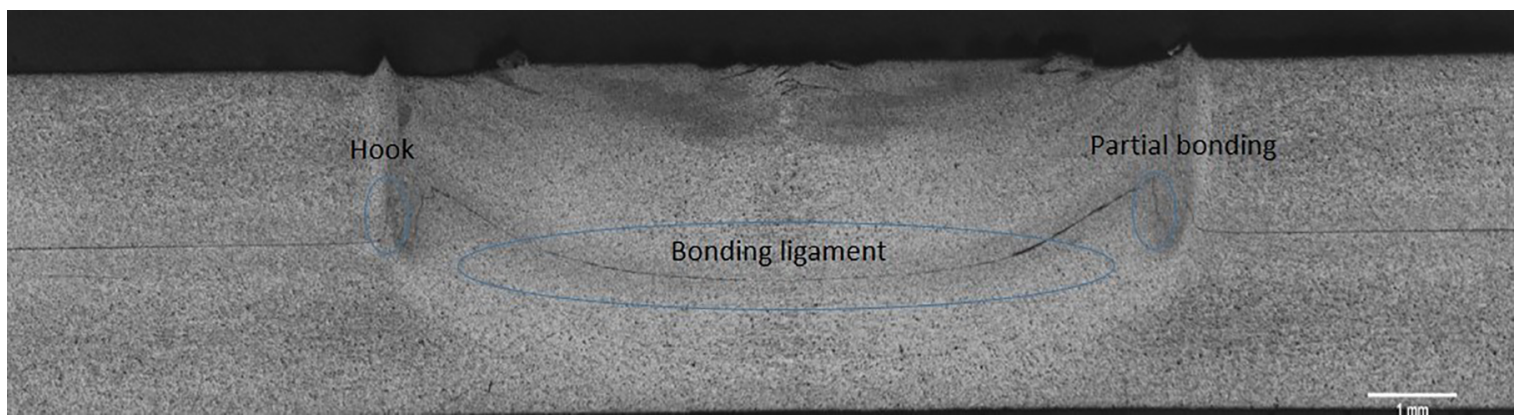

Figure 4. OM macrographs of a typical FSSW connection cross section showing the weld zones, geometric/metallurgical features. 
However the center of the bonding ligament is shaped in the begging of the process ${ }^{5,7}$

The partial bonding is a transition region where the bonding strength between sheets varies as a function of process parameters.

The formation mechanism of the hook is rather complicated; however it is important to study because the hook diminishes the integrity of the joint, since a crack can initiate and propagate in this area ${ }^{7}$. In order to investigate the formation of hook in the refill FSSW process in detail, a magnified image of hook is shown in Figure 6.

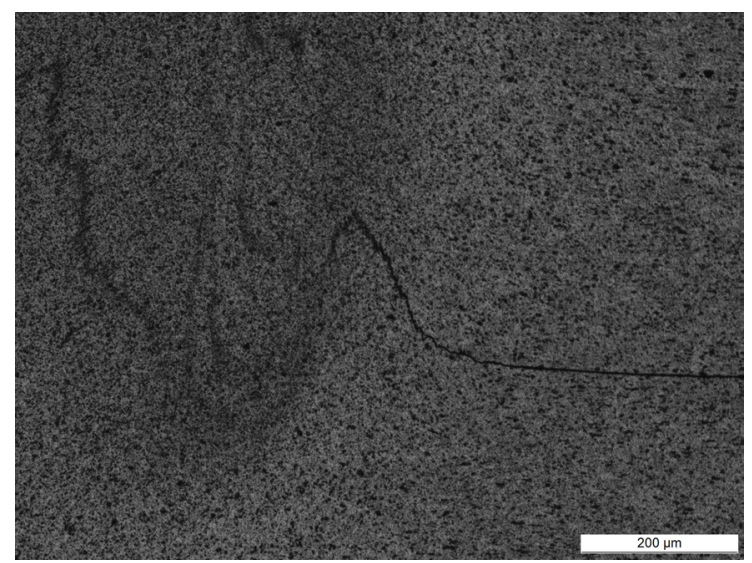

Figure 6. Detail of the hook.

As it can be observed, the hook presents an upside down V shaped appearance, and this geometry is associated to the material flow on the second and third stage of the refill FSSW process. During his study Suhuddin et al ${ }^{9}$, concluded that the plasticized lower sheet material, during the second stage, was extruded into the upper sheet, and the original interface generating an inverted "V" shape in the weld. Rosendo et al ${ }^{3}$ reported hook formation during the third stage, whereby the sleeve extruded the material from the center of the weld to close the keyhole created by the retracted pin. The edges of the inverted "V" shaped interface are pushed sideways and upward while its center was pushed downward by the retracted sleeve. ${ }^{2,3,8,9}$.

The shape of the hook change according to the combination of process parameters. It means that the hook height and the width had a correlation with rotational speed, plunge speed and plunge depth. The hook height is defined as the distance between the original interface and the hook tip. The width of the welding zone of the experimental material corresponds approximately to the distance between the tips of both hooks. The final hook height is believed to be controlled by two factors: the amount of plasticized material and the material flow ${ }^{5}$.

Figure 7 shows the influence of the hook size on the lap shear strength (LSS). This figure reveals that the smaller hook size has the highest resistance and the best parameter was: 1300 $\mathrm{rpm}, 1.4 \mathrm{~mm}$ and $4 \mathrm{~mm} / \mathrm{s}$ that results in the smallest hook size.

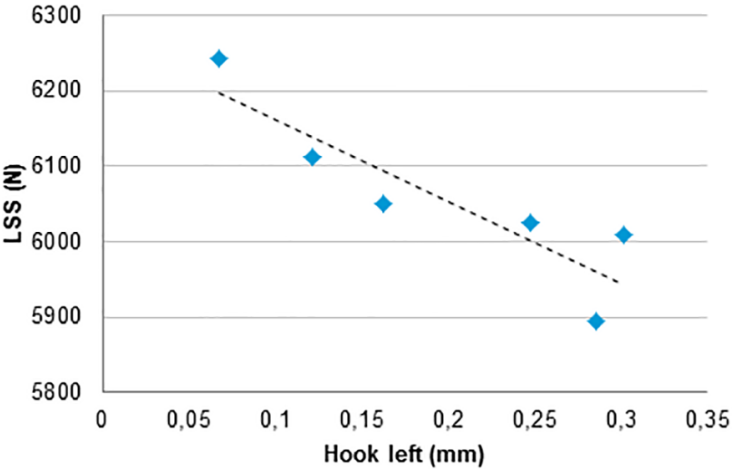

Figure 7. LSS x Hook size.

The hook increased when the rotation speed decreased and the plunge depth increased. It is possible to analyze that the hook height affect the mechanical properties ${ }^{6,10,11}$.

\section{Conclusions}

Based on the results of this experiment, the following conclusions can be stated:

- The processing parameters greatly affect the geometry of the hook.

- Three macroscopi regions are inherent to refill FSSW joints.

- The hook height had a correlation with plunge depth and rotational speed.

- $\quad$ Plunge depth was the most significant parameter affecting the weld strength.

- $\quad$ Tensile shear strength decreased with increasing hook height.

\section{References}

1. Schilling C, Santos JF, inventors; Helmholtz-Zentrum GZ, assignee. Method and device for linking at least two adjoining work pieces by friction welding. US patent 6722556B2. 1999 Nov 18.

2. Sato YS, Kokawa H, Enomoto M, Jogan S. Microstructural evolution of 6063 aluminum during friction-stir welding. Metallurgical and Materials Transactions: A. 1999;30(2):2429-2437.

3. Rosendo TS. Estudo do desempenho mecânico de solda(s) ponto por fricção $(F S p W)$ da liga 6081-T4 [tese]. Rio Grande do Sul: PPGEM, UFRGS; 2009.

4. Silva A, Rosendo TS, Ramos FD, Bergman L, Mazzaferro JAE, Santos JF, et al. Friction Spot And Friction Stir Spot Welding Processes - A Literature Review. Bulletin of National R\&D Institute for Welding and Material Testing. 2007.

5. Cao JY, Wang M, Kong L, Guo LJ. Hook formation and mechanical properties of friction spot weldind in alloy 6061-T6. Journal of Materials Processing Technology. 2016;230:254-262.

6. Tier M, Silva A, Rosendo T, Ramos FD, Mazzaferro JAE, Mazzaferro $\mathrm{CCP}$, et al. The influence of weld microstructure on mechanical properties of refill friction spot welding of 5042 aluminium alloy. In: $7^{\text {th }}$ International Friction Stir Welding Symposium; 2008 may 20th-22 ${ }^{\text {nd }}$. Awaji Island, Japan: SAE Technical Papers; 2008. p. 2287. 
7. Su PU, Gerlich AP, North TH, Bendzsak GJ. Intermixing in dissimilar friction stir spot weds. Metallurgical and Materials Transactions: A. 2006;38:584-595.

8. Shen Z, Yang X, Yang S, Zhang Z, Yin Y. Microstructure and mechanical properties of friction spot welded 6061-T4 aluminum alloy. Materials and Design. 2014;54:766-778.

9. Suhuddin UFH, Ficher V, Santos JF. The thermal cycle during the dissimilar friction spot welding of aluminum and magnesium alloy. Scripta Materialia. 2013;68(1):87-90.
10. Olea CAW, Roldo L, Santos JF, Strohaecker TR. A sub-structural analysis of friction stir welded joints in an AA6056 Al-alloy in T4 and 66 temper conditions. Materials Science and Engineering: A. 2007;454-455:52-62.

11. Fujimoto M, Koga S, Abe N, Sato Y, Kokawa H. Microstructural analysis of stir zone of Al alloy produced by friction stir spot welding. Science and Technology of Welding and Joining. 2008;13(7):663-670. 